\title{
Effect of COVID-19 stressors on healthcare workers' performance and attitude at Suez Canal university hospitals
}

\author{
Mohammed Goda Elbqry ${ }^{1}$, Fatma Mohmed Elmansy ${ }^{1}$, Abeer Ezzat Elsayed ${ }^{2}$, Bassam Mansour ${ }^{3}$, Ashraf Tantawy ${ }^{4}$, \\ Maged Bahi Eldin ${ }^{5}$ and Haydy Hassan Sayed ${ }^{4 *}$
}

\begin{abstract}
Background: Coronavirus disease 2019 is an emerging respiratory disease caused by a novel coronavirus effect on 10-20\% of total healthcare workers and was first detected in December 2019 in Wuhan, China. This study was designed to assess effect of COVID-19 stressors on healthcare workers' performance and attitude. A descriptive cross sectional research design was used. A convenient sample (all available healthcare workers) physicians "112,", nurses "183," pharmacists "31," and laboratory technicians "38" was participated to conduct aim of the study. Utilize the study with two tools; online self-administrated questionnaire to assess level of knowledge, attitude, and infection control measures regarding coronavirus disease 2019 and COVID-19 stress scales to assess the varied stressors among healthcare workers.
\end{abstract}

Results: More than three quarter of the studied participants had satisfactory level of knowledge and infection control measures. Approximately all of the studied participants had positive attitude regarding COVID-19. A total of $57.4 \%$ of the studied medical participants had moderate COVID-19 psychological stress levels, while $49.1 \%$ of the studied paramedical participants had moderate COVID-19 psychological stress levels. But less than one quarter had severe COVID-19 psychological stress levels. There is a significant correlation between COVID-19 psychological stressor levels and satisfactory level of knowledge among medical participants.

Conclusion/implications for practice: Most of healthcare workers had satisfactory level of knowledge, infection control measures, and positive attitude regarding COVID-19. Most of them had moderate COVID-19 psychological stress levels.

Keywords: COVID-19 psychological stressors, Healthcare workers performance

\section{Background}

The outbreak of a new coronavirus (COVID-19, formerly known as nCoV-2019) was first reported in Wuhan, China, since late December 2019. COVID-19 is an acute fatal disease that may cause progressive respiratory complications which end up with death $[1,2]$. In April 2020, there was more than 1 million cases of infected patients all over 60 countries around the world.

\footnotetext{
* Correspondence: drhaydy@yahoo.com

${ }^{4}$ Psychiatric and Neurological Diseases, Faculty of Medicine, Suez Canal University, Ismailia City, Egypt

Full list of author information is available at the end of the article
}

Based on the data from 72,314 cases, $14 \%$ had serious and $5 \%$ of the patients had critical conditions, with mortality rate of $2.3 \%$ [3]. At the national level, Egypt has recorded more than 500 cases and 60 deaths, while in the Suez Canal University Hospital, it is a local record; 10 nurse cases and 3 physicians have been recorded $[4,5]$.

Healthcare workers (HCWs) are exposed to multiple infectious diseases, which transmitted through the blood or other body fluids and/or airborne infectious [6]. HCWs are exposed to highest levels of risk when they are in direct contact with the patients [7] or while they care for patients or by exposure to patient biological

\section{Springer Open}

() The Author(s). 2021 Open Access This article is licensed under a Creative Commons Attribution 4.0 International License, which permits use, sharing, adaptation, distribution and reproduction in any medium or format, as long as you give appropriate credit to the original author(s) and the source, provide a link to the Creative Commons licence, and indicate if changes were made. The images or other third party material in this article are included in the article's Creative Commons licence, unless indicated otherwise in a credit line to the material. If material is not included in the article's Creative Commons licence and your intended use is not permitted by statutory regulation or exceeds the permitted use, you will need to obtain permission directly from the copyright holder. To view a copy of this licence, visit http://creativecommons.org/licenses/by/4.0/. 
samples or environment. Which make them worry of being infected and transmitting infection to family members and have negative effects on them (C [8].; D [9].). Stress and job burnout among the HCWs are more during a pandemic outbreak of an infectious disease [10].

Widespread infection and fatalities among the HCWs are causing social and mental pressures on them which have been reported previously for SARS and MERS and currently for the COVID-19 disease [11]. A conceptual framework for healthcare workers' stress when caring for COVID-19 patients, including four variables (the worry of social isolation, the discomfort caused by the protective equipment, the difficulties and anxiety of infection control, and the workload of caring for patients) [11].

The lack of knowledge has been associated with higher infection rate [12]. Misunderstandings among HCWs have delayed controlling efforts to provide necessary treatment [13], led to the rapid spread of infection in hospitals, and put patients' lives at risk. Knowledge can influence the perceptions of HCWs due to their past experiences and beliefs [14].

Several socio-demographic (e.g., gender, age, profession) and psychological variables (e.g., social support, self-efficacy) have been associated with increased level of stress, anxiety, depressive symptoms, and insomnia in HSWs [15]. HCWs who have been confident about infection control have had the lowest level of stress [16]. HCWs, particularly those working in emergency units, ICUs, and infectious disease wards, have experienced different levels of stress, anxiety, and insomnia. In addition, they have faced loneliness and rigid expectations, which can lead to anger, anxiety, and uncertainty of the outbreak [17]

\section{Aim of the study}

The aim of this study was to assess effect of COVID-19 stressors on healthcare workers' performance and attitude at Suez Canal University hospitals.

\section{Methods}

Design

A correlational cross sectional research design was used.

\section{Setting}

This study was conducted at Suez Canal University hospitals (established in 1993 at Ismailia City, serves Canal and Sina area, involved more than 15 departments with 4 large building and more of multidisciplinary healthcare workers).

\section{Participants}

Convenient accidental sample of all available healthcare workers. Electronic online questionnaires were sent to all available healthcare workers to meet aim of the study, actually involved medical staff (physicians) "112," paramedical staff (healthcare workers who provide clinical services to patients under the supervision of a physician) nurses "183," pharmacists "31," and laboratory technicians " 38 " who were agreed and recruited in the study between 1 and 14 July 2020 .

\section{Tools for data collection}

Tools were utilized to collect data for the current study, as the following:

\section{Tool (I): online self-administrated questionnaire}

it adopted by the researchers based on related literature review and other studies, sent online through registered contact's way to all available healthcare workers [18-20]. Consisted of the following:

Part 1 Part 1 used to assess the studied healthcare workers' demographic characteristics, such as age, gender, occupation, degree, years of experience, marital status, place of before working here, place of residence, smoking.

Part 2 Consisted of 15 items, used to assess the studied healthcare workers brief level of knowledge regarding COVID-19 (definition, risk factors, mode of transmission, clinical manifestation, prevention, and management).

Scoring system: Adapted from Zhou et al. [19]. The total score of knowledge will be from 0 to 15 grades, each correct answer was given one grade, $\geq 60 \%$ will be considered an adequate level of knowledge.

Part 3 Consisted of 20 items, used to assess the studied healthcare workers' level of infection control measures.

Scoring system: Adapted from Al-Hanawi et al. [21]. The total score of knowledge will be from 0 to 20 grades, each correct answer was given one grade, $\geq 60 \%$ will be an adequate level of practice.

Part 4 Part 4 used to assess the studied healthcare workers' attitude toward COVID-19, consists of 6 questions, adopted from Al-Hanawi et al. [21].

Scoring system: The level of agreement on 3 points Likert scale; with $3=$ "agree," $2=$ "neutral," $1=$ "disagree"

\section{Tool (II): COVID-19 stress scales}

Sent online although through registered contact's way; developed by Taylor et al. [22] in May 2020 and translated in to Arabic valid language by Elgilany and Elwasify [23] in June 2020, is a stable 5-factor solution was identified, was used to assess COVID-related stress and 
anxiety symptoms: (1) danger and contamination fears, (2) fears about economic consequences, (3) xenophobia

(4) compulsive checking and reassurance seeking, and

(5) traumatic stress symptoms about COVID-19.

Scoring system: Adopted from [10, 11], is a 30 -item questionnaire; total scores will range from 0 to 120 degree

While (0) means very well, (1) means mild, (3) mean moderate, (4) severe. Totally, score under 50 are likely to be well, 50-66 are likely to have a mild, 66-82 are likely to have moderate, while over 82 and over are likely to have a severe mental disorder.

\section{Content validity}

Tools of data collection were tested for validity by a panel of 5 experts in the related field to determine whether the included items are comprehensive, understandable, applicable, clear, and suitable to achieve the aim of the study.

\section{Content reliability}

Coefficient of reliability of the evaluating tools I and II was measured by Cronbach's $\alpha$ alpha, the reliability scores were 0.81 and 0.80 which indicate high internal consistency of the used tools.

\section{A pilot study}

A pilot study was carried out on $10 \%$ of healthcare workers to test clarity, applicability, feasibility, and to estimate the needed time to complete each tool. Necessary modifications were done.

\section{Field work}

\section{Preparatory phase}

- The study started and completed within planned time "two months."

- Contacts' ways obtained from healthcare workers who agreed to participate in the study after explaining the aim of the study.

- Data collection established in various sessions among participants based on their rooster time.

- The researchers' contacts were being available on call for any interpretations post sending online questionnaires' link.

\section{Implementation phase}

- Data collection was being collected in suitable time away from working's time.

- Data collection was being collected using a valid and registered healthcare workers' contacts to send online questionnaires' links through e-mail contact, WhatsApp, Facebook messenger, and so on.
- Data was collected through online questionnaires within 2 weeks by the researchers using a simplified English and Arabic language among participants.

- Meeting online through zoom or webinar video apps for any interpretation.

\section{Administrative design}

- An official letter for data collection was obtained from the head of ethics committee to start data collection in Faculty of Nursing "code No. 81, dated 6/2020."

- An official permission for data collection was obtained orally from president of Suez Canal University and written consent from director of Suez Canal University hospitals.

- Online consent of the healthcare workers was obtained.

\section{Ethical considerations}

The ethical research consideration in this study includes the following:

- The objectives and aims of the study were clarified to the participants.

- The studied healthcare workers were assured of maintaining anonymity and confidentiality of collected data.

- The studied healthcare workers were informed that they have the right to withdraw from the study at any time, in despite of online consent.

\section{Statistical design}

The raw data coded and entered into SPSS system files (version 22) will be conduct using the following statistical measures:

- Descriptive statistics will be used including frequency; distribution, mean, and standard deviation will be used to describe different characteristics.

- Univariate analyses, including Student $t$ test, ANOVA test, Mann Whitney test, and KruskalWallis test will be used to test the significance of results of quantitative variables.

- Spearman's rank correlation coefficient or Spearman's rho is a nonparametric measure to assess how well the relationship between two variables can be described using a monotonic function. 


\section{Significance of results}

Non-significant $-P>0.05$

Significant $-P \leq 0.05$

\section{Results}

Table 1 showed that less than half of the studied medical staff $45.5 \%$ aged $29:<39$, while less than half of the studied paramedical staff $45.6 \%$ aged $20:<29$. Regarding sex, more half of participants were female, while less than two-third were 6-10 years of experience. About more than half of the participants married, and had urban residence.

Figure 1 presented that half of the studied participants $50 \%$ were nurses, while less than one quarter $9 \%$ were pharmacists.

Table 2 portrayed than more than three quarter of the studied participants had satisfactory level of knowledge and infection control measures. Approximately, all of the studied participants had positive attitude regarding COVID-19.

Figure 2 illustrated that more than half (57.4) of the studied medical participants had moderate COVID-19 psychological stress levels, while approximately half (49.1\%) of the studied paramedical participants had moderate COVID-19 psychological stress levels. But few

Table 1 Frequency distribution of demographic characteristics of the studied staff (medical and paramedical) $(n=364)$

\begin{tabular}{|c|c|c|c|c|}
\hline \multirow[t]{2}{*}{ Variables } & \multicolumn{2}{|c|}{ Medical (112) } & \multicolumn{2}{|c|}{ Paramedical (252) } \\
\hline & $N$ & $\%$ & $N$ & $\%$ \\
\hline \multicolumn{5}{|l|}{ Age } \\
\hline $20:<29$ & 37 & 33 & 115 & 45.6 \\
\hline $29:<39$ & 51 & 45.5 & 90 & 35.7 \\
\hline$\geq 39$ & 24 & 21.4 & 47 & 18.7 \\
\hline \multicolumn{5}{|l|}{ Sex } \\
\hline Female & 65 & 58 & 144 & 57.1 \\
\hline Male & 47 & 42 & 108 & 42.9 \\
\hline \multicolumn{5}{|c|}{ Years of experience } \\
\hline $1-5$ & 36 & 32.1 & 99 & 39.3 \\
\hline $6-10$ & 76 & 67.9 & 139 & 53.6 \\
\hline$\geq 11$ & 0 & 0 & 18 & 7.1 \\
\hline \multicolumn{5}{|c|}{ Marital status } \\
\hline Single & 33 & 29.5 & 104 & 41.3 \\
\hline Married & 77 & 68.8 & 140 & 55.6 \\
\hline Divorced & 2 & 1.8 & 6 & 2.4 \\
\hline Widowed & 0 & 0 & 2 & 0.7 \\
\hline \multicolumn{5}{|l|}{ Residence } \\
\hline Urban & 84 & 75 & 175 & 69.4 \\
\hline Rural & 28 & 25 & 28 & 30.6 \\
\hline
\end{tabular}

participant less than one quarter had severe COVID-19 psychological stress levels.

Table 3 presented that there is a significant correlation between COVID-19 psychological stressors levels and satisfactory level of knowledge among medical participants, while there is no significant correlation with other items.

\section{Discussion}

The crucial role of HCWs during a pandemic as front liners is vital and massive, making them more susceptible to anxiety and stress due to overwhelming health care systems in addition to fear of acquiring the infection (N [24].). So our study aims to assess effect of COVID-19 stressors on healthcare workers' performance and attitude at Suez Canal University hospitals. Convenient accidental sample of "112" physicians, "183" nurses, "31" pharmacists, and "38" laboratory technicians involved in this study.

In our study, less than half of the studied medical staff $45.5 \%$ aged $29:<39$, while less than half of the studied paramedical staff $45.6 \%$ aged $20:<29$. Regarding sex, more half of participants were female, while less than two-third had 6-10 years of experience. About more than half of the participants were married, and had urban residence. Half of the studied participants 50\% were nurses, $31 \%$ were physician, $10 \%$ were technician while 9\% were pharmacists. Another study in Saudi Arabia was concentrated on frontline HCWs including doctors (30\%) and nurses (62\%) in critical and high risk areas mainly ICUs and ER (44.8\%).

In this study, more than three quarter of the studied participants had satisfactory level of knowledge and infection control measures. Approximately all of the studied participants had positive attitude regarding COVID19. These finding goes with another study in Nigeria which reported that majority of the participants were highly aware and knowledgeable about the COVID-19 pandemic [25]. Similarly, a Ugandan study had reported about $70 \%$ of their respondents had sufficient level of knowledge [26] also in an Iranian study it was found that $99 \%$ of respondents had excellent knowledge level regarding the disease modes of transmission but regarding the disease symptoms only $86 \%$ had sufficient knowledge [27]. This finding is inconsistent with the finding of study conducted in India which found that healthcare workers had insufficient knowledge about COVID-19 pandemic and study by Akshaya S.B. et al. [28] which revealed that HCWs have insufficient knowledge about COVID-19 but showed positive perceptions of COVID19 transmission prevention. Both sample size and geographical variations may be responsible for the discrepancies in the findings. 


\section{Participants}

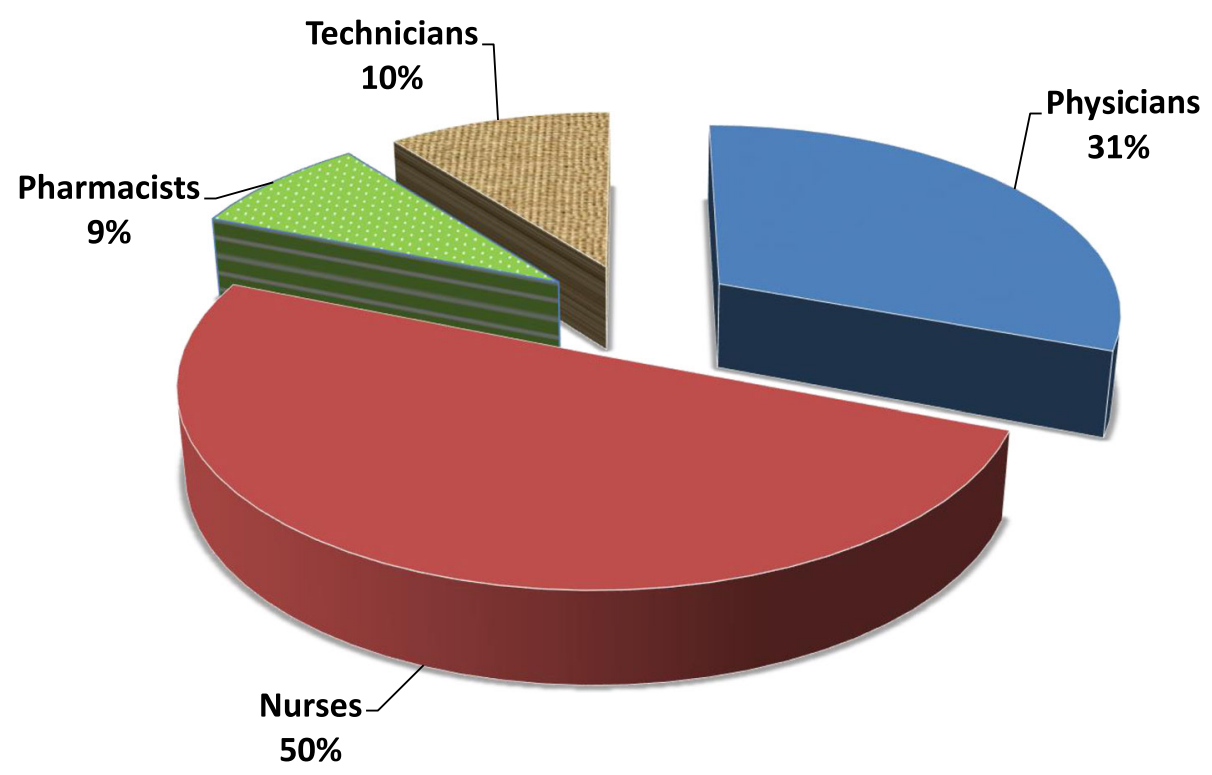

Fig. 1 Frequency distribution of the studied participants (medical and paramedical) $(n=364)$

In this study, more than half 57.4 of the studied medical participants had moderate COVID-19 psychological stress levels, while approximately half $49.1 \%$ of the studied paramedical participants had moderate COVID-19 psychological stress levels. But few participant less than one quarter had severe COVID-19 psychological stress levels. This may be due to during the COVID-19 outbreak, HCWs have been coping with high emotional distress due to the risk of exposure, excessive workload/ work hours, moral ethical dilemmas, and shortage of protective personal equipment [29]. In Pakistan, large numbers of HCWs reported moderate (42\%) to severe (26\%) psychological distress [15]. In Canada, $47 \%$ of
HCWs have reported a need for psychological support [30].

Another study by Hui Wang et al. reported that less than $60 \%$ of participants has moderate or severe stress for all the stress items and the level of stress among frontline healthcare workers was below the medium level, which may be related to the powerful interventions taken by the government as they directed substantial attention during the initial stage toward COVID-19 as it requires protection measures especially for frontline staff. It also reported that the stress among nurses or married staff members was higher than that of others caring for COVID-19 patients. Married healthcare

Table 2 Level of knowledge, infection control measures, and attitude score of the studied staff (medical and paramedical) regarding COVID-19 $(n=364)$

\begin{tabular}{|c|c|c|c|c|c|}
\hline \multirow[t]{3}{*}{ Variables } & & \multicolumn{2}{|c|}{ Medical (112) } & \multicolumn{2}{|c|}{ Paramedical (252) } \\
\hline & & \multicolumn{2}{|c|}{ Satisfactory score } & \multicolumn{2}{|c|}{ Satisfactory score } \\
\hline & & $N$ & $\%$ & $N$ & $\%$ \\
\hline \multirow[t]{2}{*}{ Total knowledge } & Score & 106 & 94.6 & 230 & 91.3 \\
\hline & Mean $\pm S D$ & \multicolumn{2}{|c|}{$11.33 \pm 1.65$} & \multicolumn{2}{|c|}{$11.05 \pm 1.74$} \\
\hline \multirow[t]{2}{*}{ Total infection control measures } & Score & 98 & 87.5 & 231 & 91.7 \\
\hline & Mean \pm SD & \multicolumn{2}{|c|}{$13.75 \pm 2.07$} & \multicolumn{2}{|c|}{$14.30 \pm 2.11$} \\
\hline \multirow[t]{2}{*}{ Variable } & & \multicolumn{2}{|c|}{ Positive } & \multicolumn{2}{|c|}{ Positive } \\
\hline & & $N$ & $\%$ & $N$ & $\%$ \\
\hline \multirow[t]{2}{*}{ Total attitude } & Score & 112 & 100 & 238 & 94.4 \\
\hline & Mean \pm SD & \multicolumn{2}{|c|}{$14.98 \pm 1.71$} & \multicolumn{2}{|c|}{$14.76 \pm 2.18$} \\
\hline
\end{tabular}




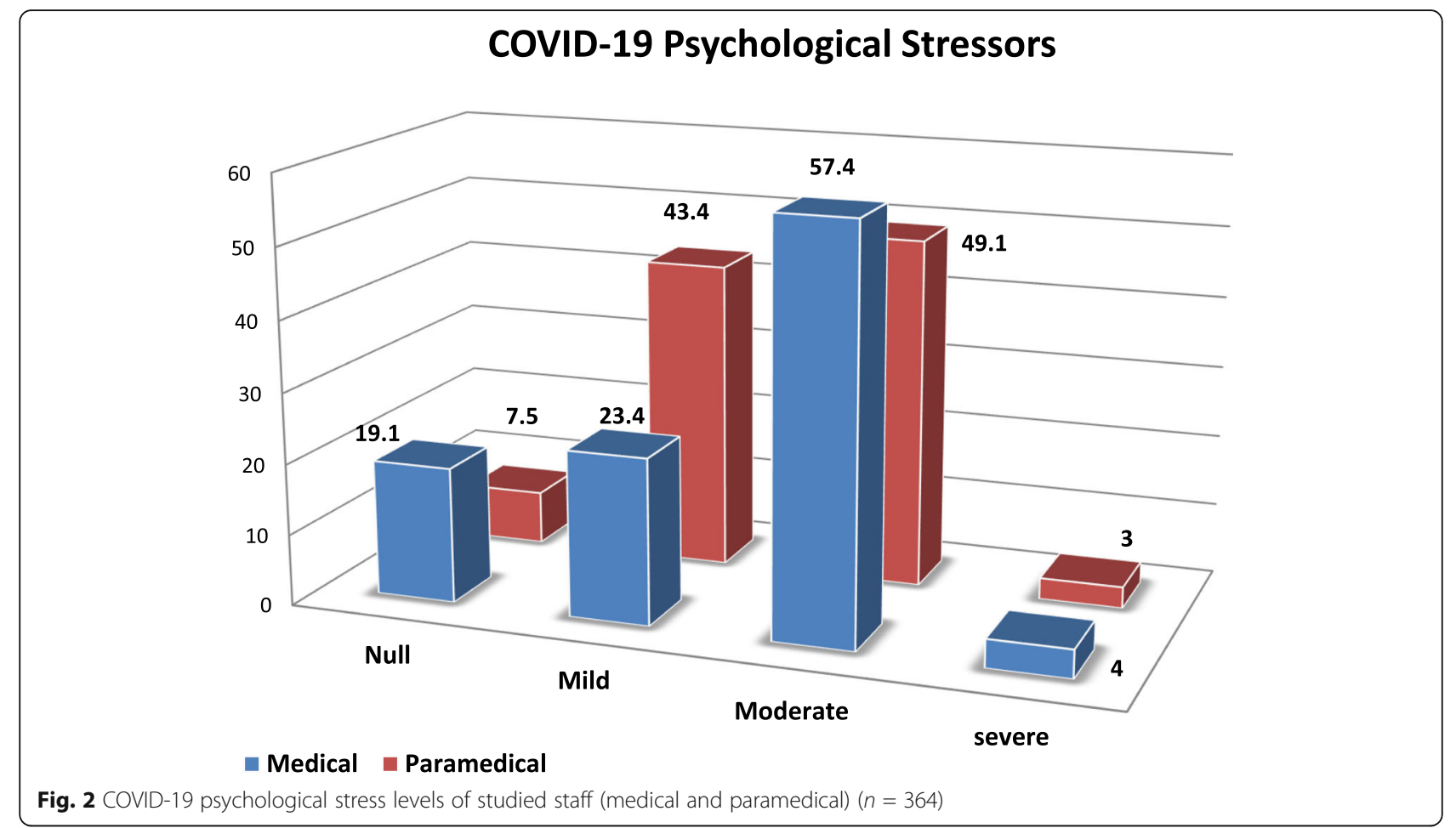

workers were more stressed than unmarried staff were, possibly because they have a family to worry about.

Another study in Saudi Arabia [31] used Generalized Anxiety Disorder (GAD-7) as an anxiety severity screening tool to measure the levels of anxiety and found moderately high and very high anxiety scores at $8 \%$ and $2 \%$ respectively to COVID-19. Also found that $15 \%$ of HCWs considered rescheduling or changing their duty in order to avoid patients with COVID-19.This higher degree of stress was probably due to the fact that COVID-19 is a new emerging virus with uncertain contagiousness, rapidity of spread, and degree of information associated with it [32].

In this study, there is a significant correlation between COVID-19 psychological stressors levels and satisfactory level of knowledge among medical participants. These

Table 3 Correlation between knowledge level, infection control measures, attitude level, and COVID-19 psychological stress levels of studied staff (medical and paramedical) $(n=364)$

\begin{tabular}{|c|c|c|c|c|c|c|c|c|c|c|c|}
\hline \multirow[t]{3}{*}{ Variables } & & \multicolumn{8}{|c|}{ Stress level } & \multirow[t]{3}{*}{$x^{2}$} & \multirow{3}{*}{$\begin{array}{l}P \\
\text { value }\end{array}$} \\
\hline & & \multicolumn{2}{|c|}{ Very well } & \multicolumn{2}{|c|}{ Mild } & \multicolumn{2}{|c|}{ Moderate } & \multicolumn{2}{|c|}{ Severe } & & \\
\hline & & $N$ & $\%$ & $N$ & $\%$ & $N$ & $\%$ & $N$ & $\%$ & & \\
\hline \multirow[t]{6}{*}{ Medical subject } & \multicolumn{11}{|c|}{ Knowledge level } \\
\hline & Satisfactory & 58 & 100 & 26 & 81.2 & 19 & 100 & 3 & 100 & 15.84 & $0.001 *$ \\
\hline & \multicolumn{11}{|c|}{ Infection control measures level } \\
\hline & Satisfactory & 48 & 82.8 & 30 & 93.8 & 17 & 89.5 & 3 & 100 & 2.83 & 0.418 \\
\hline & \multicolumn{11}{|c|}{ Attitude level } \\
\hline & Positive & 58 & 100 & 32 & 100 & 19 & 100 & 3 & 100 & Equal & Equal \\
\hline \multirow[t]{6}{*}{ Paramedical subject } & \multicolumn{11}{|c|}{ Knowledge level } \\
\hline & Satisfactory & 136 & 91.9 & 59 & 85.5 & 29 & 100 & 6 & 100 & 6.29 & 0.098 \\
\hline & \multicolumn{11}{|c|}{ Infection control measures level } \\
\hline & Satisfactory & 135 & 91.2 & 66 & 95.7 & 24 & 82.8 & 6 & 100 & 5.03 & 0.169 \\
\hline & \multicolumn{11}{|c|}{ Attitude level } \\
\hline & Positive & 137 & 92.6 & 66 & 95.7 & 29 & 100 & 6 & 100 & 3.24 & 0.355 \\
\hline
\end{tabular}


finding could be because HCWs awareness in infection prevention and control measures, effective communication and proper information dissemination as well as emotional support would have a major impact to minimize the level of anxiety and stress that will be encountered [33]. Evidence-based education and training of HCWs on preparedness for the pandemic is proven to be essential to improve the experience, skills, and mental well-being of hospital staff during a pandemic [34]. Also, the lack of knowledge has been associated with higher infection rate [12] and HCWs who have been confident about infection control have had the lowest level of stress [16].

\section{Conclusion}

Most of the health care workers had satisfactory level of knowledge and infection control measures. Approximately all of them had positive attitude regarding COVID-19.

Most of the health care workers had moderate COVID-19 psychological stress levels. But few of them had severe COVID-19 psychological stress levels.

There is a significant correlation between COVID-19 psychological stressor levels and satisfactory level of knowledge among medical participants.

\section{Limitations}

Feeling of tiredness, restricted time, and nature of pandemic situation among healthcare workers are main limitation to involve more participants.

Online questionnaire may be less reliable way than observation technique to check level of infection control measure.

Small size convenience sample which cannot be seen as descriptive of HCWs in other settings.

\section{Abbreviations}

COVID-19: Coronavirus disease2019; HCWs: Healthcare workers; SARS: Severe acute respiratory syndrome; MERS: Middle East respiratory syndrome; ICUs: Intensive care units; ER: Emergency room; GAD: Generalized anxiety disorder

\section{Acknowledgements}

This study is recruited in an emergency time to valuable concerns, delighted to appreciate all healthcare workers who participated in the study, or withdrawal due to busy time or exhaustion, directors of hospitals and president of Suez Canal University for valuable support, also all thanks to Ethics Committee in the Faculty of Nursing and the Faculty of Medicine for their effort and significant criticism.

\section{Authors' contributions}

Study conception and design: HS, ME, FE, AE. Data collection: HS, ME, BM, MB. Data analysis and interpretation: HS, FE, AE, MB. Drafting of the article: $H S, M E, F E, A T$. Critical revision of the article: HS, ME, BM, AT. All authors had read and approved the manuscript.

\section{Funding}

Spent by research team.
Availability of data and materials

Available data and material.

\section{Ethics approval and consent to participate}

- An official letter for data collection was obtained from the head of ethics committee to start data collection in Faculty of Nursing "code No. 81, dated 6/2020."

- An official permission for data collection was obtained orally from president of Suez Canal University and written consent from director of Suez Canal University hospitals.

- Online consent of the healthcare workers was obtained.

The ethical research consideration in this study includes the following:

- The objectives and aims of the study were clarified to the participants.

- The studied healthcare workers were assured of maintaining anonymity and confidentiality of collected data.

The studied healthcare workers were informed that they have the right to withdraw from the study at any time, in despite of online consent.

\section{Consent for publication}

Online consent of the healthcare workers was obtained for publication.

Consent from other authors were obtained.

\section{Competing interests}

The authors declare no conflict of interest.

\section{Author details}

${ }^{1}$ Medical Surgical Nursing, Faculty of Nursing, Suez Canal University, Ismailia City, Egypt. ${ }^{2}$ Medical Microbiology and Immunology, Faculty of Medicine, Suez Canal University, Ismailia City, Egypt. Infectious and Endemic Diseases, Faculty of Medicine, Suez Canal University, Ismailia City, Egypt. ${ }^{4}$ Psychiatric and Neurological Diseases, Faculty of Medicine, Suez Canal University, Ismailia City, Egypt. ${ }^{5}$ Medical Psychiatric Department, Medical Academic Armed Force, Cairo, Egypt.

Received: 24 November 2020 Accepted: 7 January 2021

Published online: 26 January 2021

\section{References}

1. Huang C et al (2020) Clinical features of patients infected with 2019 novel coronavirus in Wuhan, China. Lancet 395:497-506

2. Wu F, Zhao S, Yu B et al (2020) A new coronavirus associated with human respiratory disease in China. Nature 79(7798):265-269

3. Wu Z, McGoogan JM (2020) Characteristics of and important lessons from the coronavirus disease 2019 (COVID-19) outbreak in China: summary of a report of 72314 cases from the Chinese Center for Disease Control and Prevention. JAMA 323(13):1239-1242. https://doi.org/10.1001/jama.2020. 2648

4. Egyptian Ministry of Health (2020) Updates on COVID-19 (coronavirus disease2019) local situation. Ministry of Health website, Egypt

5. Suez Canal University's News.: Suez Canal University's hospital statistical record (27/6/2020-10.00 pm):, Facebook website ( قاخبار جام قان (السو س س (ال).

6. Shiao JS-C, Koh D, Lo L-H, Lim M-K, Guo YL (2007) Fators predicting nurses' consideration of leaving their job during the SARS outbreak. Nurs Ethics 14: 5-17

7. World Health Organization (2003) Consensus document on the epidemiology of severe acute respiratory syndrome (SARS). World Health Organization, Geneva

8. Hammen (2018) Risk factors for depression: an autobiographical review. Annu Rev Clin Psychol 14:1-28

9. Koh MK, Lim SE, Chia SM, Ko F, Qian VN et al (2005) Risk perception and impact of severe acute respiratory syndrome (SARS) on work and personal lives of healthcare workers in Singapore: what can we learn? Med Care 43(7):676-682

10. Maunder RG et al (2006) Long-term psychological and occupational effects of providing hospital healthcare during SARS outbreak. Emerg Infect Dis 12: 1924

11. Almutairi AF, Adlan AA, Balkhy HH, Abbas OA, Clark AM (2018) "It feels like I'm the dirtiest person in the world.": exploring the experiences of healthcare providers who survived MERS-CoV in Saudi Arabia. J Infect Public Health 11:187-191 
12. Cheng VC-C, Wong S-C, Yuen K-Y (2020) Estimating coronavirus disease 2019 infection risk in health care workers. JAMA Network 3:e209687

13. Hoffman SJ, Silverberg SL (2018) Delays in global disease outbreak responses: lessons from H1N1, Ebola, and Zika. Am J Public Health 108(3): 329-333

14. Vinck P, Pham P, Bindu K, Bedford J, Nilles E (2019) Institutional trust and misinformation in the response to the 2018-19 Ebola outbreak in north Kivu, DR Congo: a population-based survey. Lancet Infect Dis 19(5):529-536. https://doi.org/10.1016/S1473-3099(19)30063-5

15. Spoorthy MS (2020) Mental health problems faced by healthcare workers due to the COVID-19 pandemic-a review. Asian J Psychiatr 51:102119

16. Chua SE, Cheung V, Cheung C, MCAlonan GM, Wong JWS et al (2004) Psychological effects of the SARS outbreak in Hong Kong on high-risk health care workers. Can J Psychiatr 49:391-393

17. Centers for Disease Control and Prevention (2003) Severe acute respiratory syndrome-Taiwan. Morb Mortal Wkly Rep 52:461-466

18. National Health Commission of China. Update on epidemic situation of novel-coronavirus infected-pneumonia. (Accessed on 1.30 am - 24/6/2020: http://www.nhc.gov.cn/xcs/yqtb/202002/ac1e98495cb04d36b0d0a4e1 e7fab545.shtml

19. Zhou M, Tang F, Wang Y, Nie H, Zhang L, You G, Zhang M (2020) Knowledge, attitude and practice regarding COVID-19 among healthcare workers in Henan, China. J Hosp Infect 105:183-187

20. World Health Organization. Coronavirus disease (COVID-19) pandemic. 2020; https://www.who.int/emergencies/diseases/novel-coronavirus-2019. (Accessed on 11.00 pm - 22/72020: https://covid19.who.int/).

21. Al-Hanawi MK, Angawi K, Alshareef N, Qattan A, Helmy HZ, Abudawood Y, Alqurashi M, Kattan WM, Kadasah NA, Chirwa GC, Alsharqi O (2020) Knowledge, attitude and practice toward COVID-19 among the public in the Kingdom of Saudi Arabia: a cross-sectional study. Front Public Health 8: 217. https://doi.org/10.3389/fpubh.2020.00217

22. Taylor S, Landry CA, Paluszek MM, Fergus TA, McKay D, Asmundson GJG (2020) Development and initial validation of the COVID Stress Scales. J Anxiety Disord 72:102232. https://doi.org/10.1016/j.janxdis.2020.102232

23. Elgilany A and Elwasify M. Validation of the COVID Stress Scales in Egypt. Unpublished article is under processing, Neurology department, Mansoura University. 2020.

24. Wilson N, Baker M, Crampton P, Mansoor O (2005) The potential impact of the next influenza pandemic on a national primary care medical workforce. Hum Resour Health 3(1):7

25. Ogolodom MP, Mbaba AN, Alazigha N, Erondu OF, Egbe NO et al (2020) Knowledge, attitudes and fears of HealthCare workers towards the Corona virus disease (COVID-19) pandemic in south-south, Nigeria. Health Sci J Sp Iss 1:002

26. Olum R, Chekwech G, Wekha G et al (2020) Coronavirus disease-2019: knowledge, attitude, and practices of health care workers at Makerere University teaching hospitals Uganda. Front Public Health 8:181

27. Maleki S, Najafi F, Farhadi K, et al. Knowledge, attitude and behavior of health care workers in the prevention of COVID-19. BMG Medical Education, under review. 2020.

28. Akshaya SB, Wafa AA, Jamal R, Mohammadjavad AM, Deepak KB (2020) Knowledge and perceptions of COVID-19 among health care workers: crosssectional study. JMIR Public Health Surveill 6(2):e19160

29. Moghbelli H, Ellithy K, Eslami Z (2020) SCCM COVID-19 rapid-cycle survey 2 report

30. United Nations. Policy Brief: COVID-19 and the need for action on mental health. 2020.

31. Temsah M-H, Al-Sohime F, Alamro N et al (2020) The psychological impact of COVID-19 pandemic on health care workers in a MERS-CoV endemic country. J Infect Public Health 13(6):877-882

32. Barry M, Al Amri, Memish ZA (2020) COVID-19 in the shadows of MERS-CoV in the Kingdom of Saudi Arabia. J Epidemiol Glob Health 10(1):1-3

33. Chan AO, Huak CY (2004) Psychological impact of the 2003 severe acute respiratory syndrome outbreak on health care workers in a medium size regional general hospital in Singapore. Occup Med (Lond) 54:190-196

34. Aiello MY, Khayeri S, Raja N, Peladeau D, Romano ML et al (2011) Resilience training for hospital workers in anticipation of an influenza pandemic. J Contin Educ Heal Prof 31(1):15-20

\section{Publisher's Note}

Springer Nature remains neutral with regard to jurisdictional claims in published maps and institutional affiliations.

\section{Submit your manuscript to a SpringerOpen ${ }^{\circ}$ journal and benefit from:}

- Convenient online submission

- Rigorous peer review

- Open access: articles freely available online

High visibility within the field

- Retaining the copyright to your article

Submit your next manuscript at $\boldsymbol{\sim}$ springeropen.com 